\section{NIH in the dark over conflicts of interest}

The US National Institutes of Health (NIH) relies on an honour system that leaves it unaware of the details of situations in which its external grantees have financial conflicts of interest, according to a report released on 17 January.

The report, from the inspector-general of the Department of Health and Human Services, found that nearly half of the NIH's 24 grant-making institutes and centres were unable to provide any of the financial disclosure reports they received from external institutions between 2004 and 2006. Of the 438 reports that were produced, $89 \%$ were devoid of details describing the conflicts or how they were being managed.

Such details are not required under current rules; the report recommended that this change. But the NIH disputed that advice, saying that if it agreed to accept detailed reports, it would be held accountable for oversight duties that are properly the job of grantees' institutions.

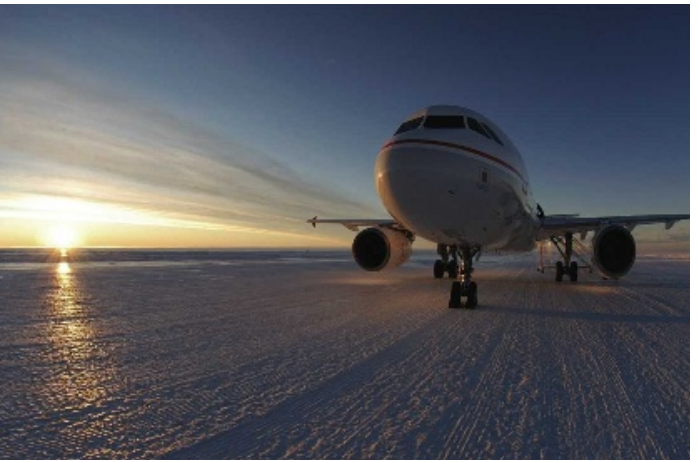

A plane sits on the new ice runway in Antarctica.

\section{Ice runway knocks weeks off journey to Antarctica}

The first scheduled air link between

Antarctica and Australia opened this month, giving Australian researchers a 4.5-hour trip to the frozen continent. Until now, they have had to travel for weeks by sea.

The first passenger flight carrying scientists landed on 11 January on a blue ice runway some 60 kilometres from the Casey research station. The initial trip made by air included researchers studying penguin ecology, and more than 20 scientists are expected to travel to Antarctica using the new flight path by the end of January.

The air link, which is operational between October and February, will run at least 10 flights a year. The Airbus A319 is fitted with long-range fuel tanks to allow it to travel to and fro without refuelling in Antarctica.

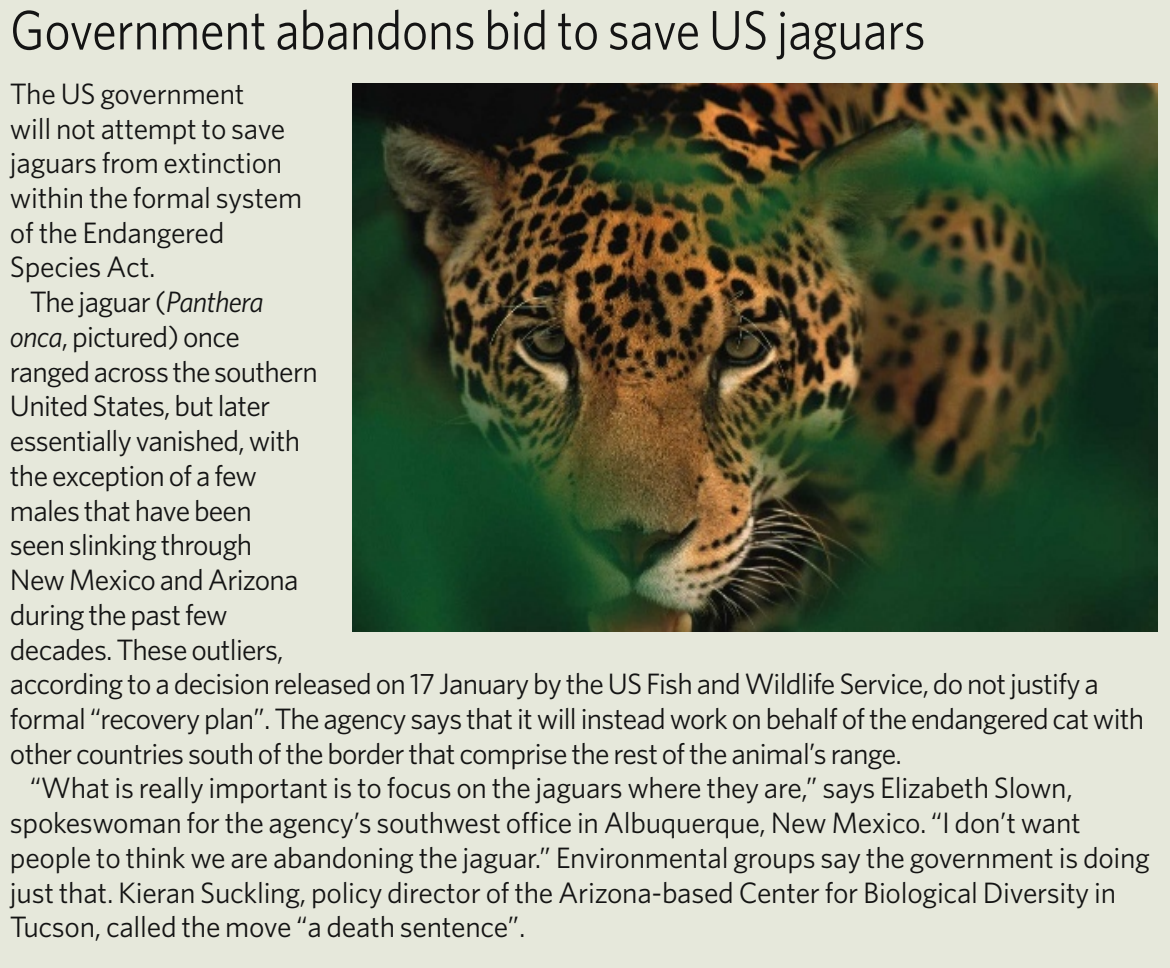

\section{Early-stage human embryos cloned from adult cells}

A Californian company says it has brought human cloning research to a new level with the efficient production of five cloned earlystage human embryos called blastocysts from adult skin cells.

Stemagen, which is based in La Jolla, hopes that its achievement will lead to the use of cloning techniques for biomedical research and, potentially, therapy. But first it will need to go the next step - using cells from a patient to generate blastocysts and then establish self-propagating lines of embryonic stem cells that, as clones, would be genetically identical to the patient.

Cloned human blastocysts have been reported before, but previously they have been made from human embryonic stem cells. The findings were reported last week in Stem Cells (A. French et al. Stem Cells doi:10.1634/stemcells.2007-0252; 2008).

\section{UK government under pressure over physics cuts}

The UK government is being forced to defend its funding levels for physics. Research grants are expected to be cut by at least $25 \%$ despite a budget increase of $13.6 \%$ over three years for the Science and Technology Facilities Council (STFC), which awards physics funding.

Documents obtained through the freedom of information act by a group of concerned physicists show that the STFC warned the government in advance that such cuts would mean fewer grants and reduced operation of key facilities.

Giving evidence to an inquiry on 21 January, Ian Diamond, head of Research Councils UK, the umbrella group for the country's research-funding councils, said the STFC would not be the only council affected by the budget changes. "I suspect there will be reductions in success rates [for research applications] across the board," he said.

\section{European registry makes stem-cell use transparent}

Europe has launched a registry to give researchers, regulators and the general public access to broad information about all available human embryonic stem-cell lines developed in Europe and their use.

Sponsored by the European Commission, the European Human Embryonic Stem Cell Registry went live on 18 January at www.hescreg.eu.

The repository will provide an efficient research tool. But the commission also hopes that it will make use of the ethically sensitive cell lines fully transparent in a region where each nation has different regulations. For example, scientists may derive new stem-cell lines from embryos if they are based in Britain, but not if they are in Germany, where the registry will be hosted.

Scientists involved in the project say that sharing information and materials may help limit the number of new lines generated. 